\title{
Fatores que influenciam o uso do Quadro Interativo Multimédia (QIM): Um estudo no norte de Portugal
}

Factores que influyen en el uso de la Pizarra Digital Interactiva (PDI): Un estudio realizado en el norte de Portugal

Factors influencing the use of Interactive Whiteboard (IWB): A study in northern Portugal

\section{Volumen 18, Número 3 \\ Setiembre-Diciembre}

pp. 1-24

Este número se publica el 1 de setiembre de 2018

DOI: https://doi.org/10.15517/aie.v18i3.34303

\author{
Natália Lopes \\ Joaquim Escola \\ Manuela Raposo-Rivas
}

Revista indizada en REDALYC, SCIELO

Revista distribuida en las bases de datos:

LATINDEX, DOAJ, REDIB, IRESIE, CLASE, DIALNET, SHERPA/ROMEO, QUALIS-CAPES, MIAR

Revista registrada en los directorios:

ULRICH'S $, \underline{R E D I E}, \underline{R I N A C E}, \underline{\text { OEI }}$ MAESTROTECA, PREAL, $\underline{\text { CLACSO }}$ 


\title{
Fatores que influenciam o uso do Quadro Interativo Multimédia (QIM): Um estudo no norte de Portugal
}

Factores que influyen en el uso de la Pizarra Digital Interactiva (PDI): Un estudio realizado en el norte de Portugal

Factors influencing the use of Interactive Whiteboard (IWB): A study in northern Portugal

\author{
Natália Lopes ${ }^{1}$ \\ Joaquim Escola² \\ Manuela Raposo-Rivas ${ }^{3}$
}

\begin{abstract}
Resumo: Por força do tempo em que vivemos, é imperativo que a escola apanhe o "TGV" das Novas Tecnologias da Informação e da Comunicação, pois com elas são promovidos novos métodos e estratégias de ensino e a adaptar-se aos novos interesses/necessidades dos alunos. O Ministério da Educação português, sensível a esta nova realidade de adaptação constante aos desafios de uma sociedade tecnológica, tem feito um esforço para dotar as escolas de tecnologias adequadas aos tempos em que vivemos, nomeadamente instalando Quadros Interativos Multimédia (QIM) nas salas de aula. Neste artigo apresentam-se alguns resultados do estudo realizado sobre "o cosmos" do QIM nas escolas do ensino básico do Norte de Portugal. Seguindo uma metodologia mista, com finalidade exploratória e descritiva, o objetivo foi mostrar os fatores que estão a condicionar a integração e o uso do QIM nas salas de aula. Para isso, aplicaram-se dois questionários, um a 45 diretores e outro a 1471 professores, pertencentes a 117 agrupamentos escolares (52,94\% da população). Os resultados mostram que nem a idade dos professores, nem o ano de escolaridade influenciam o uso do QIM, mas pelo contrário a disciplina que se leciona condiciona o seu uso. Conclui-se que, na perspectiva dos diretores e professores, a Matemática (75,4\%), o Português (39,4\%) e Estudo do Meio (28,8\%) são as áreas curriculares mais adequadas para a integração curricular do QIM.
\end{abstract}

Palavras-chave: tecnologia educativa, educação, docentes.

Resumen: Por exigencia del momento en que vivimos, se impone que la escuela tome el "tren de alta velocidad" de las Nuevas Tecnologías de Información y Comunicación, pues con ellas se potencian nuevos métodos y estrategias de enseñanza, y a adaptarse a los nuevos intereses y necesidades del alumnado. El Ministerio de Educación portugués, sensible a esta nueva realidad de adaptación constante a los desafíos de una sociedad tecnológica, ha realizado un esfuerzo por dotar a las escuelas de tecnologías adecuadas a los tiempos en que vivimos, particularmente instalando Pizarras Digitales Interactivas (PDI) en las aulas. En este artículo, se presentan algunos resultados del estudio realizado sobre "el universo" de las PDI en las escuelas de enseñanza básica del Norte de Portugal. Con una metodología mixta y finalidad explotatoria y descriptiva, su objetivo es averiguar qué factores están condicionando la integración y uso de las PDI en las aulas. Para ello, se aplicaron dos cuestionarios a 45 directores y 1471 docentes pertenecientes a 117 agrupamientos escolares $(52,94 \%$ de la población). Los resultados muestran que ni la edad de los docentes, ni el año de escolaridad influyen en el uso de la PDI; sin embargo, la materia que se imparte condiciona su uso. Se concluye que, desde la óptica de directores y dicentes, Matemáticas (75,4\%), Portugués $(39,4 \%$ y Conocimiento del Medio $(28,8 \%)$ son las áreas curriculares más apropiadas para la integración curricular de la PDI.

Palabras clave: tecnología educativa, educación, docentes.

\footnotetext{
1 Professora auxiliar convidada da Universidade de Trás-os-Montes e Alto

Douro, Portugal. Dirección electrónica: natamlopes@hotmail.com

2 Professor auxiliar da Universidade de Trás-os-Montes e Alto Douro, Portugal.

Dirección electrónica: jescola@utad.pt

3 Profesora de la Univesidad de Vigo, España. Dirección electrónica: mraposo@uvigo.es
}

Artículo recibido: 2 de abril, 2018

Enviado a corrección: 20 de junio, 2018

Aprobado: 13 de aqosto, 2018 


\begin{abstract}
Due to the time in which we live, it is necessary that the school picks up the "high-speed train" of the New Information and Communication Technologies, because with them new methods and teaching strategies are promoted, and adapt to the new students' interests and needs. The Portuguese Ministry of Education, sensitive to this new reality of constantly adapting to the challenges of a technological society, has made an effort to provide schools with appropriate technologies to the time in which we live, particularly installing Interactive Whiteboard (IWB) in classrooms. This article presents some results of the study on "the universe" of IWBs in elementary schools in NorthernPortugal. With a mixed methodology and exploratory and descriptive purpose, Its objective is to find out what factors are affecting the integration and use of IWB in the classrooms. For that, two questionnaires were applied to 45 directors and 1471 teachers, belonging to 117 school groups (52.94\% of the population). The results show that neither the teachers' age nor the schooling year influence the use of IWBs. However, the subject that is taught determines their use. It is concluded that, from the viewpoint of directors and teachers, Mathematics $(75,4 \%)$, Portuguese $(39,4 \%)$ and Study of the Environment $(28,8 \%)$ are the most appropriate curricular areas for the curricular integration of Interactive whiteboards.
\end{abstract}

Key Words: educational technologies, education, teachers.

\title{
1. Introdução
}

Embora a educação sempre tenha utilizado "tecnologias" para realizar a mediação entre quem aprende e quem ensina, em pleno século $X X I$, a tecnologia ocupa lugar de destaque em todas as atividades do nosso dia-a-dia. A escola não pode fugir a esta nova realidade, tornando-se, por isso, tarefa imprescindível saber utilizar as denominadas Tecnologias da Informação e da Comunicação, em geral, e o Quadro Interativos Multimédia (QIM) em particular. No entanto, o que percebemos é que, a cada nova tecnologia, existem medos e ameaças quanto à suplantação humana. É aceitável que quando surge uma nova tecnologia, a primeira atitude seja de desconfiança e de rejeição, contudo, com a introdução de TIC mais recentes, as mais antigas não são abandonadas ou renegadas sendo que todas coexistem. Uma invenção puxa outra. É uma história sem fim. Briggs e Burke (2004) mostram-nos, cronologicamente, que a televisão precedeu ao computador, do mesmo modo que a impressão gráfica antecedeu o motor a vapor, a rádio antecedeu a televisão, e as estradas de ferro e os navios a vapor precederam os automóveis e os aviões. A cada evolução técnica, uma nova etapa histórica se torna possível.

A verdade é que certas inovações técnicas e tecnológicas abrem novos caminhos para a educação e para a aprendizagem e quando pensamos em tecnologia a favor da educação, devemos vê-la como um conjunto de ferramentas que proporcionam ao professor várias vantagens, como a capacidade para adquirir as informações necessárias à construção do conhecimento ao longo da sua vida. A soma dos métodos antigos com as novas descobertas tecnológicas dá aos professores o suporte necessário para o desenvolvimento das suas atividades. Usar a tecnologia a favor da educação é saber utilizá-la como suporte auxiliar na procura da qualidade do processo de ensino e aprendizagem. É evidente para muitos 
pedagogos que as TIC fazem parte da escola e não poderão ser vistas como o pesadelo descrito por George Orwell pois, para outros, estas ainda são vistas como "inimigo".

Assim, acreditamos que o equilíbrio entre o novo e o velho, a inovação e a tradição deverão convergir para criar atitudes e práticas conducentes à aquisição de saberes essenciais construídos a partir de uma forte intervenção do sujeito de aprendizagem, criando condições que levem os jovens a construir o seu conhecimento. As TIC têm que ser encaradas como uma oportunidade de ensino que ajudam a construir a aprendizagem. Elas não são "boas" nem "más" em si mesmo, o seu valor está totalmente sujeito à intenção pedagógica do utilizador. Como tal, o professor não precisa de ter medo de ser substituído nem necessita de "concorrer" com as TIC. Ambas as partes devem unir esforços em proveito de um ensino e de uma aprendizagem mais criativa, autónoma, colaborativa e interativa.

Porém, o facto de vivermos a era digital e enfrentarmos desafios constantes, oriundos de novas tecnologias nas nossas vidas, não significa que queiramos professores adeptos incondicionais das TIC porque o recurso às tecnologias jamais poderá ser entendido como a panaceia para ultrapassar todos os problemas inerentes às dificuldades no processo ensino/aprendizagem. Significa apenas que, se nos apropriarmos de conhecimentos tecnológicos que permitam conhecer bem esses recursos, poderemos saber as suas vantagens e desvantagens, riscos e possibilidades e assim transformá-los em ferramentas úteis, em alguns momentos, e dispensá-las noutros. Por este motivo, cabe a nós, agentes educativos, mobilizar estas tecnologias no sentido de as rentabilizar no processo ensino/aprendizagem, fazendo com que haja um equilíbrio entre estes recursos e todos os outros já existentes nas escolas. Terá que haver um "meio-termo" porque ninguém poderá apoiar-se na escola do passado nem dormir sobre os louros educacionais outrora obtidos (Gardner, 1999).

Quando pensamos no impacto que as inovações oriundas da Sociedade da Informação ou Era Digital causam na educação, é possível perceber que os alunos de hoje têm acesso a uma infinidade de recursos tecnológicos, que influenciam o seu modo de estudar, de aprender, pesquisar e perceber o mundo. O professor, nesse contexto, enfrenta o desafio ou o dilema de se apropriar desses recursos e utilizá-los de forma significativa no processo ensino/aprendizagem. Os professores que lecionam e têm mais de vinte anos são, segundo Prensky (2001), imigrantes no ciberespaço, ou seja, nasceram noutro meio e aprenderam a construir conhecimento de forma diferente do que a geração denominada "nativos digitais". Assim, podemos compreender que a forma de trabalho do professor imigrante digital difere e 
muito da forma como os seus alunos percebem o conhecimento e a sua produção. Trabalhar com esses nativos digitais e captar a sua atenção é um desafio para o professor que não domina essas tecnologias.

\section{Referencial Teórico}

Nos últimos anos, também em Portugal tem havido esforços substanciais dos governantes e das escolas para melhorar o equipamento dos estabelecimentos escolares em matéria de TIC, fundamentalmente através do Plano Tecnológico da Educação que começou a tornar real a integração das Tecnologias da Informação e da Comunicação no universo educativo (Escola, Gomes e Raposo-Rivas, 2016), implicando mudanças nos contextos e nos processos de ensino e de aprendizagem. É perante a conjuntura de modernização tecnológica da escola portuguesa que surge o Quadro Interativo Multimédia, como mais um recurso didático que procura, no contexto da sala de aula, pelo seu caráter motivador e simplicidade de utilização, constituir-se como resposta a algumas das dificuldades, dos problemas e desafios que se fazem sentir na educação.

Assim, a integração dos quadros interativos nas salas de aulas começa a ser uma realidade. Porém, embora já se façam presentes nas salas de aula, ainda não possuem a centralidade do velho quadro-negro, mas é necessário reconhecer a possível substituição do consolidado quadro-negro, dando mais rapidez à exposição dos conteúdos e, quem sabe, mais fluidez, no sentido de permitir a circulação dos referidos conteúdos. Já Lee (2010), identifica os anos 2002 e 2003 como o início de uma viragem na massificação do acesso à tecnologia por parte dos professores e sublinha que neste mesmo período, o custo dos projetores e do QIM atingiu preços suficientemente baixos podendo, desta forma, as escolas apostar na sua aquisição.

Estamos na "Era do QIM" (Lopes, Escola e Raposo-Rivas, 2015, p. 8). O QIM é considerado como peça basilar na sala de aula (Lopes, Escola e Raposo-Rivas, 2016) para a organização de conteúdos, para facilitar a comunicação e a interação, para a aquisição e construção de novos conhecimentos, para o desenvolvimento das capacidades de autonomia, para a promoção da motivação e interesse e para a atenção e concentração. Com a chegada do QIM à escola, as salas de aula "apresentam novos cenários de ensino e aprendizagem" (Lopes, 2015, p. 396). É um excelente recurso, essencialmente para:

(...) diversificar estratégias e metodologias; apoiar a exposição da aula; consolidar conteúdos; facilitar a compreensão da informação; fazer a revisão de matéria; 
introduzir conteúdos; realizar exercícios; motivar; captar a atenção; debater ideias; avaliar aprendizagens, ou seja, é um excelente veículo para facilitar o ensino e a aprendizagem. (Lopes, 2015, p. 393)

Na verdade, a chegada do QIM pode causar uma revolução no ensino, pois com ele, como que por magia, os alunos e os professores veem o conhecimento a passar dos seus dedos para uma tela, onde tudo ganha cor e movimento. Perante esta prerrogativa, o papel do professor e do aluno muda, ou pelo menos deveria mudar. Para que o professor passe a usar o QIM no ensino, é preciso revolucionar a sua forma de ensinar desde o momento da planificação da aula ao momento da sua concretização. O QIM pode revolucionar a pedagogia de ensino e enriquecê-la. É realmente de extrema importância que o professor se forme para as tecnologias pois, "a forma como utilizamos as tecnologias na escola devem sofrer uma alteração, ou seja, o papel tradicional da tecnologia com o professor deve dar lugar à tecnologia como parceiro no processo educativo" (Jonassen, 2007, p. 20). Porém, a simples introdução desta tecnologia nas salas de aula não revolucionará necessariamente o ensino se as práticas pedagógicas se mantiverem as mesmas. Estamos convictos que o seu uso não significa uma negação da tecnologia já aclamada, mas significa mudanças nos modos de ensinar. Porém, no que concerne ao Quadro Interativo Multimédia, vários estudos (Esteves e Lencastre, 2013; Ferreira, 2009; Folhas, 2010; Lopes 2015) demonstram que é um recurso ainda pouco utilizado nas escolas portuguesas. O QIM ainda não é usado pela maioria dos professores e os que os utilizam não aproveitam a totalidade das suas potencialidades (Guimarães e Carvalho, 2012; Lopes, 2015; Vicente e Melão, 2009).

No entanto, segundo Lopes, Escola e Raposo-Rivas (2015) o QIM desempenha um papel central na mudança do processo de ensino/aprendizagem, potenciando novas formas de ensinar e de aprender. Permite a criação de ambientes de aprendizagem mais ricos, onde os alunos têm um papel mais ativo na construção do seu conhecimento. É fácil de usar, melhora rapidamente o ensino e a aprendizagem e potencia a criatividade. $O$ processo deixa de se centrar no professor, que era o transmissor exclusivo dos saberes, e passa a centrarse mais no aluno, tornando-se mais companheiro de caminho, um orientador pedagógico, tecnológico e motivacional, dotando os alunos de maior autonomia e mais responsabilidades sobre as suas aprendizagens. O conceito de ensino passa a estar mais centrado no processo e não no produto final. 
Consideramos, portanto, fundamental perceber se o investimento que o ministério da educação português tem feito neste recurso está a ser aproveitado pelos professores, uma vez que, segundo o que observámos na nossa prática docente, ainda não é utilizado por muitos professores portugueses e aqueles que o utilizam fazem-no com pouca frequência. Julgamos essencial perceber porque é que ainda não se está a aproveitar a totalidade das potencialidades do QIM?

Nesse sentido, a âncora deste artigo é perceber se premissas como a idade dos professores, anos de escolaridade e áreas disciplinares influenciam ou não o uso do QIM em contexto de sala de aula, uma vez que muitas incertezas se colocam à sua utilização em contexto educativo. Conscientes dessas incertezas quisemos verificar "in loco" (nas escolas do ensino básico dos diferentes distritos do Norte de Portugal) como se processa essa utilização do QIM já que tem havido uma proliferação desta ferramenta pelas escolas nos últimos anos.

\section{Metodologia}

Foi traçado um desenho metodológico que esclarece os métodos, as técnicas e a amostra utilizada para responder às questões e aos objetivos da investigação, definindo assim um rumo para a pesquisa, criando uma base sustentável para todo o processo da investigação realizada (Lopes, 2015). O modelo da investigação foi misto e, à medida que se recolheram e analisaram os dados, apresentou a imagem de um funil, pois o início do estudo é representado pela extremidade mais larga do funil e ao longo que a caminhada foi prosseguindo passou da fase de exploração alargada para uma área mais restrita de análise dos dados coligidos (estudo meramente qualitativo com estudo de caso). No que concerne ao primeiro momento da investigação, a que se reporta este artigo, possui uma metodologia do tipo descritivo-exploratória (figura 1).

Figura 1

Desenho metodológico
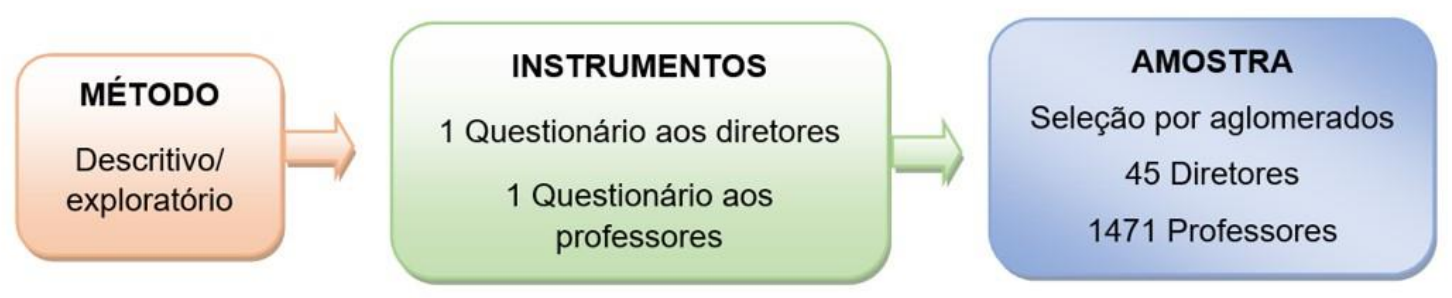

Fonte: Elaboração própria, 2018 
Descritiva uma vez que, se pretendia fazer uma descrição densa e detalhada do QIM e, exploratória porque se conhecia muito pouco da realidade em estudo e os dados recolhidos procurariam esclarecer a realidade do QIM no Norte de Portugal (distritos de Viana do Castelo, Braga, Porto, Vila Real e Bragança - figura 2).

Figura 2

Amostra abrangida nos distritos em estudo

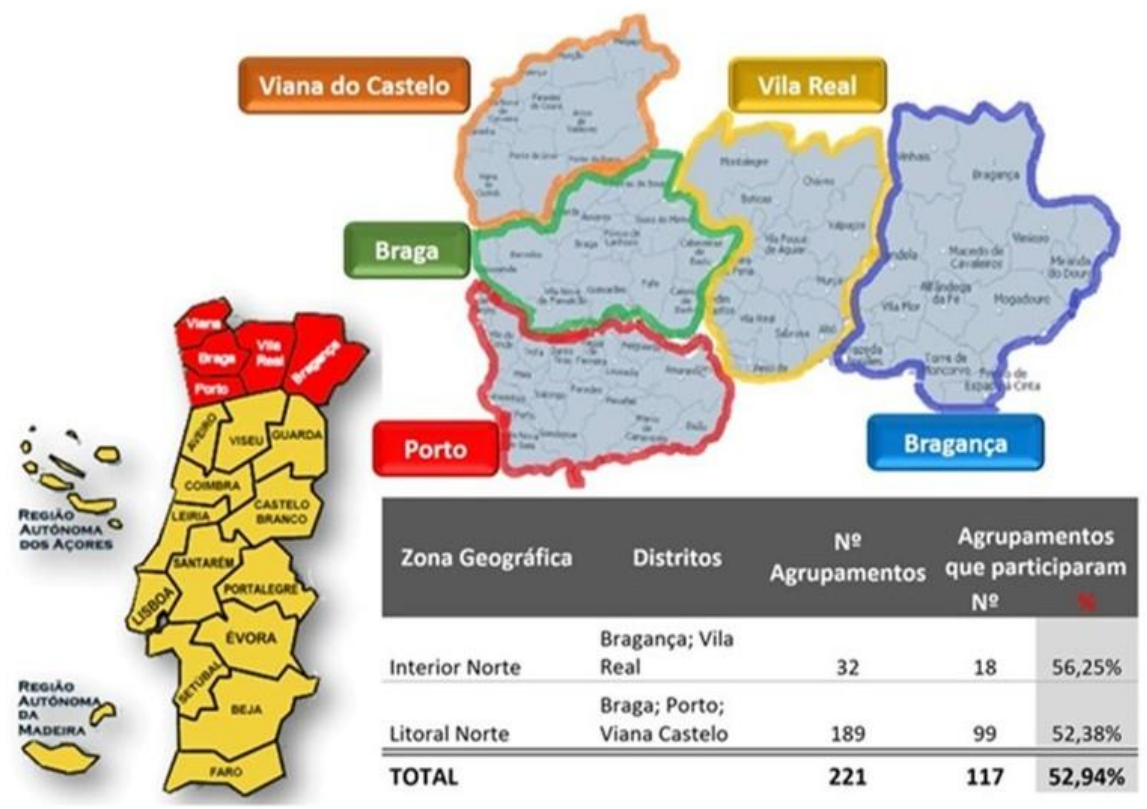

Fonte: Elaboração própria, 2018

Sendo uma investigação inscrita num plano descritivo,

(...) o objetivo era recolher dados que permitissem descrever da melhor maneira possível comportamentos, atitudes, valores e situações (...) retratar o que existe hoje em relação a um problema e a um fenómeno, por vezes mesmo descobrir relações entre fenómenos que possam ser úteis para estudos experimentais posteriores. (Coutinho, 2005, pp. 197-198)

Através do estudo exploratório como referem Raupp e Beuren (2004), procurou-se conhecer, com mais profundidade, o assunto em questão e torná-lo o mais claro possível ou delinear questões pertinentes para prosseguir na pesquisa. 
Para delimitar o universo e à amostragem em primeira instância solicitamos, à Direção Geral de Estatística da Educação e Ciência do Ministério da Educação e Ciência (DGEEC$\mathrm{MEC}$ ) o número de professores em exercício, por ciclo de escolaridade no ensino público português nos cinco distritos do Norte de Portugal. Desse modo, os participantes deste estudo seriam os professores do 1.., $2 . .^{\circ}$ e $3 . \circ$ ciclos do Ensino Básico dos cinco distritos do norte de Portugal (Viana do Castelo, Braga, Porto, Bragança e Vila Real) para que os dados recolhidos fossem o mais consideráveis possível e, os respetivos diretores por considerarmos que um diretor inovador e promotor da integração das TIC na instituição que dirige é, muitas vezes, o pilar e motor que sustenta e fomenta os processos de inovação e a criatividade na escola. O exemplo é, sem dúvida, o melhor antídoto para o marasmo e a tentação fácil do "deixa andar".

Para facilitar a perceção do caminho que percorremos na seleção da nossa amostra, apresentamos a figura 3 que esclarece que a unidade da investigação será 0 diretor/professor ou diretora/professora (por essa razão se diz que a amostra é extraída da população composta por todos os diretores/professores do norte), não obstante consideramos os aglomerados (neste caso são áreas geográficas) que fazem parte dos objetivos presentes nesta investigação. Considerando os 33.552 professores, estabelecendo o erro máximo aceitável (normalmente 5\%) e o nível de confiança (95\% - o habitual) para uma população de 33.552 professores, a amostra recomendada seria de 382 professores. Para um nível de confiança de $99 \%$, com o mesmo erro de 5\%, a amostra recomendada seria de 651 professores. Com um erro de 1\% e um nível de confiança de $99 \%$, a amostra requerida seria de 11.101 professores.

Optámos por considerar $10 \%$ da população (uma decisão particular baseada no facto de $10 \%$ da população ser suficiente, especialmente em casos como este, em que o número total de professores existente no norte de Portugal é superior a 20.000) e assim garantir, independentemente das respostas recolhidas, que a amostra estaria sempre dentro dos parâmetros de erro de $5 \%$ e nível de confiança de $99 \%$.Portanto, de um total de 33.552 professores, fariam parte da amostra, no mínimo, 3356 (não é possível dividir uma pessoa e considerar 3355.2) 
Figura 3

Passos para a seleção da amostra do estudo

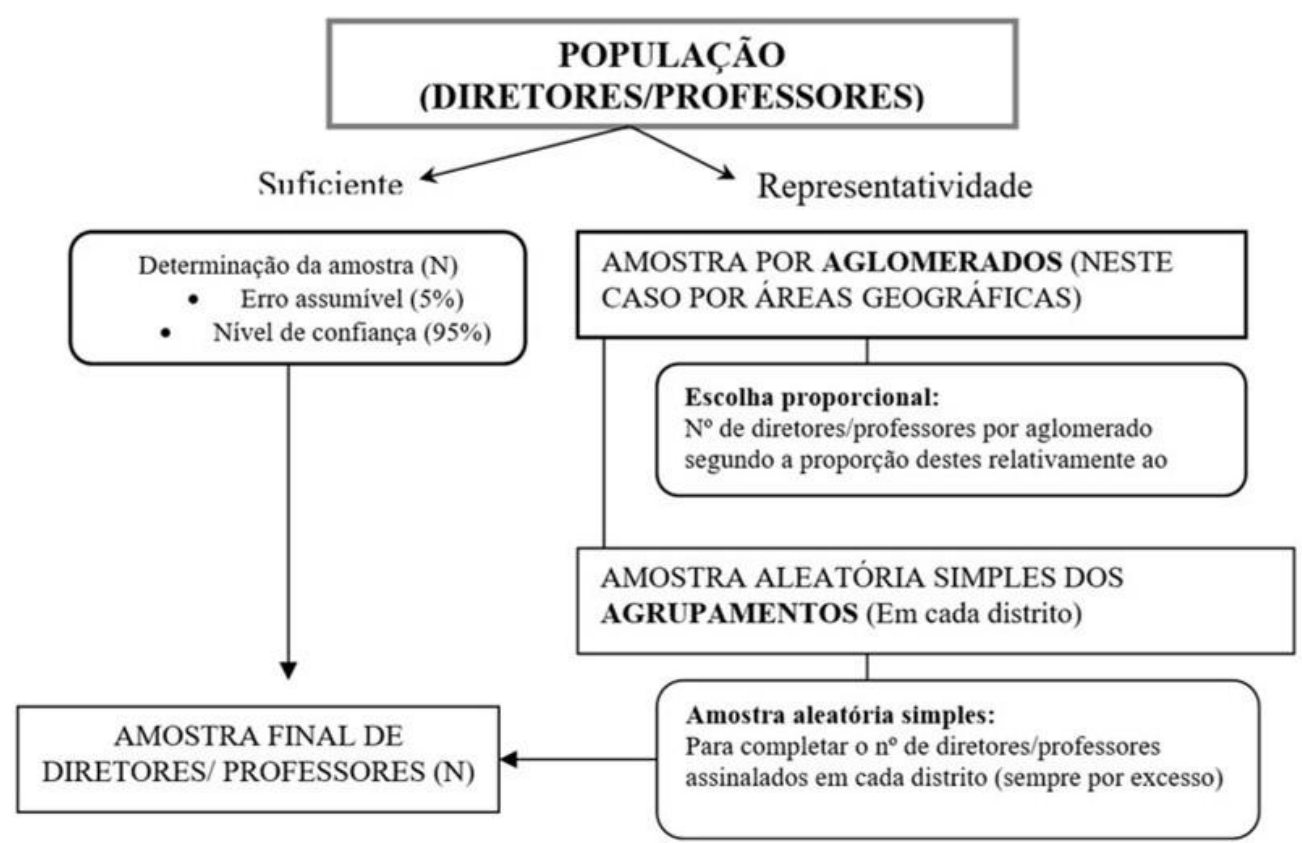

Fonte: Elaboração própria, 2018

Para garantirmos a proporcionalidade entre o total de professores e os distritos (com relação ao "peso" de cada distrito respeitante à população total dos professores), determinámos na Tabela 1 o número de professores que teriam de responder ao nosso inquérito, por questionário, por distrito, arredondado para o número mais alto.

Assim, para obtermos o número necessário de professores respondentes por distrito (mediante o que havíamos decidido), fizemos uma seleção aleatória dos agrupamentos existentes por distrito até completar o número total referido na tabela 1 (sempre por excesso), ou seja, depois de listar alfabeticamente os agrupamentos existentes por distrito e de os numerar, pedimos a alguém que fosse dizendo números até obtermos o número de agrupamentos necessários, por exemplo, no distrito de Braga, dos 58 agrupamentos, escolhemos os agrupamentos sorteados até completar (ou superar) os 883 professores. Este processo repetiu-se nos restantes distritos. 
Tabela 1

Relação entre o número de agrupamentos/professores existentes por distrito e o número de professores que deveriam responder

\begin{tabular}{cccc}
\hline Distritos & $\begin{array}{c}\text { No de } \\
\text { agrupamentos } \\
\text { por distrito }\end{array}$ & $\begin{array}{c}\text { No de professores } \\
\text { por distrito }\end{array}$ & $\begin{array}{c}\text { No de Respostas } \\
\text { necessárias } \\
\text { (Professores) }\end{array}$ \\
\hline Braga & 58 & 8.822 & 883 \\
\hline Bragança & 14 & 1.643 & 165 \\
\hline Porto & 109 & 17.603 & 1761 \\
\hline Viana do Castelo & 22 & 2.911 & 292 \\
\hline Vila Real & 18 & 2.573 & 258 \\
\hline \hline TOTAL & $\mathbf{2 2 1}$ & $\mathbf{3 3 . 5 5 2}$ & $\mathbf{3 3 5 9}$ \\
\hline
\end{tabular}

Fonte: Elaboração própria, 2018

Perante os passos seguidos e as decisões tomadas, classificámos a nossa amostra como aleatória por clusters. Neste tipo de amostragem, a seleção dos objetos (grupos naturais previamente existentes que, no nosso caso, são os agrupamentos de escolas dos 5 distritos do Norte) é aleatória, todos os elementos (professores) pertencentes aos clusters/grupos (agrupamentos) são selecionados e cada elemento da população pertence a um só grupo. Para tal, é necessário, tal como fizemos, dispor de uma listagem completa das amostras primárias (por exemplo, os agrupamentos de escolas). Os clusters são escolhidos aleatoriamente e dentro de cada cluster todos os elementos são selecionados, ou seja, só existe uma etapa de amostragem.

Neste artigo, a ênfase é colocada no objetivo relativo aos fatores que podem influenciar o uso do QIM na sala de aula, nomeadamente tratamos de aferir se fatores como o ano de escolaridade, a disciplina ou a área disciplinar, e a idade do professor influenciam a utilização do QIM. Para responder a este objetivo da investigação utilizaram-se dois inquéritos por questionário - um dirigido aos diretores dos agrupamentos de escolas públicas do ensino básico dos 5 distritos pertencentes ao norte de Portugal e outro, destinado aos professores do ensino básico desses agrupamentos.

Os questionários foram elaborados de raiz, com questões de resposta fechada e aberta atendendo ao público-alvo e aos objetivos concretos e foram respondidos por 45 diretores e 1471 professores pertencentes a 117 agrupamentos (52,94\%). Os inquéritos mostram uma boa fiabilidade tendo em conta o coeficiente Alfa de Crombach. Segundo 
George e Mallery (2003, p. 231), se o valor de Alfa é maior a 0,7 o grau de fiabilidade será aceitável, se é maior a 0,8 será bom, e se é superior a 0,9 será excelente.

À vista dos resultados obtidos na análise de fiabilidade dos questionários, considerando a classificação desses autores, pode estabelecer-se um grau de fiabilidade bom nos subconjuntos que apresentam um Alfa de Crombach com valores superiores a 0,8 (Bloco III "Utilização do QIM" do questionário dos professores assim como no total deste último), um grau considerado aceitável nos valores superiores a 0,7 (Bloco II "Equipamento e disponibilidade do QIM", Bloco III "Utilização do QIM", Bloco V "Dados relativos à formação em e para o QIM" do questionário dos diretores, bem como na sua totalidade; no Bloco II “Equipamento e disponibilidade do QIM" e Bloco IV "Problemas/ Dificuldades e Apoio/Auxílio técnico com o QIM" do questionário dos professores e no Bloco II "Expetativas em relação à formação em QIM" do questionário diagnóstico da formação). Os inquéritos no seu todo mostram, um coeficiente Alfa de Crombach $=0,745$ para os diretores, e 0,866 para os professores.

$\mathrm{Na}$ análise de dados, como a sua natureza é distinta e obriga a um tratamento diferenciado dos mesmos, privilegiou-se a técnica de análise de conteúdo para as questões abertas (Bardin, 2006; Rocha, Christo e Adalgisa, 2005) com a finalidade de as interpretar (Bardin, 2006; Quivy, 2003) e procedimentos estatísticos para as questões fechadas (Pardal e Correia, 1995), recorrendo ao software de análise de conteúdo Nvivo, na sua versão 10.0 para análise qualitativa de dados e ao software Microsoft Excel 2010, para o tratamento dos dados quantitativos e elaboração de gráficos, por se tratar de uma ferramenta adequada, não se revelar significante para o estudo em causa modelos estatísticos complexos e pelo domínio na utilização da mesma. Recorremos à estatística descritiva para considerar as frequências e as percentagens de resposta. Para avaliar corretamente a fiabilidade dos diferentes questionários optámos por utilizar a análise estatística recorrendo ao SPSS (versão IBM SPSS Statistics 20.0).

\section{Fatores que influenciam a utilização do QIM na sala de aula}

\subsection{A idade}

A maioria dos diretores intervenientes no estudo ( $n=30$, equivalente a $66,7 \%$ ) consideram, como se pode verificar na tabela 2 , que a idade do professor não condiciona a utilização do QIM, especialmente porque "há professores mais novos que usam e há professores mais novos que não usam. Há professores com mais tempo de serviço que 
usam e há professores com mais tempo de serviço que não usam. A utilização do QIM passa muito pela formação ou a sua inclinação para o uso das TIC e nada tem que ver com a idade" (Dir.16). Portanto, para esses diretores, o facto de os professores serem nativos ou imigrantes digitais não tem influência na utilização do QIM. A utilização desta tecnologia depende antes da 'Formação aos docentes' (40,0\%), da 'Vontade do professor' (33,3\%) e da sua 'Tendência para uso' (30,0\%). Para 15 diretores (33,3\%) inquiridos, a idade condiciona o uso do quadro interativo multimédia porque "os professores mais velhos sentem mais dificuldade na sua utilização" (Dir.31) e "há maior apetência por parte dos professores mais jovens para o seu uso" (Dir.34).

Tabela 2

Relação idade do professor e o uso do QIM na perspetiva dos diretores

\begin{tabular}{llcc}
\hline $\begin{array}{l}\text { A idade do professor não é um fator condicionante para o } \\
\text { uso do QIM por questões de: }\end{array}$ & Fr. & $\%$ \\
\hline Não & Formação & 11 & 36,7 \\
N=30 & Vontade do professor & 10 & 33,3 \\
& Tendência para uso & 9 & 30,0 \\
\hline A idade do professor é um fator condicionante para o uso & & \\
do QIM por questões de: & & \\
\hline Sim & Dificuldades de uso & 9 & 60,0 \\
$\mathbf{N}=\mathbf{1 5}$ & Predisposição para uso & 6 & 40,0 \\
\hline
\end{tabular}

Fonte: Elaboração própria, 2018

\subsection{Ano de escolaridade}

Se na perspetiva dos diretores a idade não é fator condicionante para a utilização do QIM, muito menos condicionante é o ano de escolaridade que os professores lecionam. De fato, para 42 diretores (93,3\%) (Cf. Tabela 3), o ano de escolaridade lecionado pelos professores não influência nem condiciona o uso desta TIC, porque 64,3\% considera que pode ser usado em qualquer nível de ensino. Um número significativo de diretores $(26,2 \%)$ acrescenta que pode ser usado em qualquer nível de ensino, mas têm de ser feitas adequações "ao nível etário dos alunos" (Dir.5). Para 23,8\% dos líderes dos agrupamentos de escolas, O QIM "tanto dá num ano como outro porque apresenta muitas ferramentas adaptáveis a qualquer ano de escolaridade" (Dir.6), ou seja, dispõe de muitas 'Potencialidades técnicas'. Também nesta questão, alguns diretores reforçam que a 
utilização do QIM depende antes do conhecimento que o professor tem sobre esta ferramenta, ou da sua vontade para o utilizar.

Na ótica de apenas 3 diretores, a utilização do QIM depende do ano de escolaridade que se leciona. No entanto, as respostas obtidas deixam entender que não está diretamente relacionado com particularidades do ano de escolaridade, mas antes "porque os QIM só estão colocados em algumas salas (por haver poucos) e, como tal, a utilização do QIM depende do ano que se leciona, pois nem todos os anos de escolaridade Ihes podem aceder" (Dir.8).

\section{Tabela 3}

\section{Relação ano de escolaridade e o uso do QIM na perspetiva dos diretores}

\begin{tabular}{llcc}
\hline $\begin{array}{l}\text { A utilização do QIM depende do ano de escolaridade que } \\
\text { se leciona: }\end{array}$ & Fr. & $\%$ \\
\hline & Conhecimento do professor & 8 & 19,0 \\
& Potencialidades técnicas & 10 & 23,8 \\
$\mathrm{Não}$ & Uso em qualquer nível de ensino & 27 & 64,3 \\
$\mathrm{~N}=\mathbf{4 2}$ & Uso em qualquer nível de ensino com & 11 & 26,2 \\
& adequações & 5 & 11,9 \\
\hline $\mathrm{Sim}$ & Vontade do professor & 3 & 100,0 \\
$\mathrm{~N}=\mathbf{3}$ & Inexistência em certas salas & &
\end{tabular}

Fonte: Elaboração própria, 2018

A tabela 4 permite verificar que, no entendimento de 1381 professores inquiridos (93,9\%), a utilização do QIM não depende do ano de escolaridade que se leciona, porque segundo $61,8 \%$ desses professores, o presumível substituto do quadro preto pode ser utilizado em qualquer nível de ensino, e 15,6\% $(n=215)$ considera até que o QIM pode ser usado em qualquer nível de ensino, mas para isso são necessárias adaptações, tal como também referiram os diretores. Alguns professores chegam ainda a considerar que O QIM pode ser usado em qualquer área disciplinar (5,1\%), para abordar qualquer conteúdo $(4,1 \%)$ e em qualquer situação da aula $(1,7 \%)$, porque é uma tecnologia que dispõe de muitos 'Recursos adequados' (5,6\%) e de imensas 'Potencialidades técnicas' (3,5\%). 
Tabela 4

Relação ano de escolaridade e o uso do QIM na perspetiva dos professores

\begin{tabular}{|c|c|c|c|}
\hline \multicolumn{2}{|c|}{ A utilização do QIM depende do ano de escolaridade que se leciona: } & \multirow{2}{*}{$\begin{array}{l}\text { Fr. } \\
82\end{array}$} & \multirow{2}{*}{$\begin{array}{l}\% \\
5,9\end{array}$} \\
\hline \multirow{14}{*}{$\begin{array}{l}\text { Não } \\
N=1381\end{array}$} & Características da aula/área disciplinar & & \\
\hline & Conhecimento do professor & 284 & 20,6 \\
\hline & Disponibilidade do QIM & 153 & 11,1 \\
\hline & Interesse dos alunos & 52 & 3,8 \\
\hline & Necessidade de uso & 52 & 3,8 \\
\hline & Potencialidades técnicas & 48 & 3,5 \\
\hline & Vontade do professor & 162 & 11,7 \\
\hline & Recursos adequados & 77 & 5,6 \\
\hline & Uso em qualquer área disciplinar & 71 & 5,1 \\
\hline & Uso em qualquer conteúdo & 57 & 4,1 \\
\hline & Uso em qualquer nível de ensino & 854 & 61,8 \\
\hline & Uso em qualquer nivel de ensino com adequações & 215 & 15,6 \\
\hline & Uso em qualquer situação da aula & 23 & 1,7 \\
\hline & Outras/Resposta questionável & 22 & 1,6 \\
\hline \multirow{7}{*}{$\begin{array}{l}\text { Sim } \\
N=90\end{array}$} & Adequado ao $1 .{ }^{\circ}$ ciclo & 29 & 32,2 \\
\hline & Adequado ao 2.9 ciclo & 16 & 17,8 \\
\hline & Adequado ao $3 .{ }^{\circ}$ ciclo & 23 & 25,6 \\
\hline & Inadequado aos mais novos & 18 & 20,0 \\
\hline & Inexistência em certas salas & 6 & 6,7 \\
\hline & Irrelevante para alunos crescidos & 17 & 18,9 \\
\hline & Outras/Resposta questionável & 6 & 6,7 \\
\hline
\end{tabular}

Fonte: Elaboração própria, 2018

Pela análise dessa mesma tabela (Cf. Tabela 4), podemos ainda apurar que para muitos dos professores a utilização do QIM depende antes do 'Conhecimento do professor' (20,6\%, correspondente a $n=284)$, 'Vontade do professor' em usar o QIM $(11,7 \%$, relativo a $\mathrm{n}=162)$, 'Disponibilidade do QIM' nas escolas (11,1\% referente a $\mathrm{n}=153)$, 'Características da aula/área disciplinar' (5,9\% correspondente a n=82), 'Interesse dos alunos' pelo uso do QIM e da 'Necessidade de uso' do professor (3,8\% relativo a $n=82$ ).

Do escasso número de professores ( $n=90$, ou $6,1 \%$ ) que considera que o uso do QIM depende do ano de escolaridade que se leciona, é importante referir que esses professores justificaram a sua convicção argumentando que o QIM é mais adequado a determinado ciclo de escolaridade, sendo o $1 .$. ciclo referenciado como o nível de ensino onde o QIM melhor se adequa. Alguns professores não indicaram o nível de ensino mais adequado para o uso 
do QIM, proferindo apenas que o seu uso é 'Inadequado aos mais novos' $(\mathrm{n}=18)$ ou 'Irrelevante para alunos crescidos' $(\mathrm{n}=17)$.

\subsection{Disciplina ou área curricular}

Até agora, ficou claro que, na perspetiva dos diretores e professores inquiridos, nem a idade do professor, nem o ano de escolaridade condicionam o uso do QIM em contexto de sala de aula. Assim sendo, quisemos também perceber se há áreas curriculares/ disciplinas em que o QIM se revela mais adequado.

Tabela 5

Relação entre as áreas curriculares/disciplinas e o uso do QIM na perspetiva dos professores

\begin{tabular}{|c|c|c|c|}
\hline \multicolumn{2}{|c|}{$\begin{array}{l}\text { Considera que existem áreas curriculares / disciplinas em que o } \\
\text { QIM se revela mais adequado? Porquê? }\end{array}$} & \multirow{2}{*}{$\begin{array}{l}\text { Fr. } \\
42\end{array}$} & \multirow{2}{*}{$\begin{array}{r}\% \\
3,0\end{array}$} \\
\hline \multirow{10}{*}{$\begin{array}{l}\text { Não } \\
N=694 \\
(47,2 \%)\end{array}$} & Adaptações & & \\
\hline & Conhecimento do professor & 58 & 8,4 \\
\hline & Facilita a aprendizagem & 37 & 5,3 \\
\hline & Potencialidades didáticas & 85 & 12,2 \\
\hline & Potencialidades técnicas & 155 & 22,3 \\
\hline & Recursos adequados & 27 & 3,9 \\
\hline & Uso em qualquer área disciplinar & 621 & 89,5 \\
\hline & Uso importante & 56 & 8,1 \\
\hline & Vontade do professor & 22 & 3,2 \\
\hline & Outras/Resposta questionável & 7 & 1,0 \\
\hline \multicolumn{2}{|c|}{$\begin{array}{l}\text { Considera que existem áreas curriculares / disciplinas em que o } \\
\text { QIM se revela mais adequado? Porquê? }\end{array}$} & Fr. & $\%$ \\
\hline \multirow{8}{*}{$\begin{array}{l}\text { Sim } \\
N=777 \\
(52,8 \%)\end{array}$} & Aprendizagem de vocabulário & 18 & 2,3 \\
\hline & Disponibilidade de recursos & 23 & 3,0 \\
\hline & Facilita a aprendizagem & 54 & 6,9 \\
\hline & Interesse/motivação & 26 & 3,3 \\
\hline & Natureza da disciplina & 527 & 67,8 \\
\hline & Potencialidades didáticas & 21 & 2,7 \\
\hline & Potencialidades técnicas & 131 & 16,9 \\
\hline & Outras/Resposta questionável & 5 & 0,6 \\
\hline
\end{tabular}

Fonte: Elaboração própria, 2018

Observando a tabela 5 percebe-se que neste aspeto as opiniões dos professores não tendem tanto para um lado como no que concerne à idade do professor ou ao nível de ensino. Na realidade, verifica-se um número superior de professores que considera existir 
áreas curriculares / disciplinas mais adequadas ao uso do QIM (777 casos, 52,8\%), mas é muito próximo do número de professores $(47,2 \%)$ que considera não existirem disciplinas mais adequadas do que outras para o uso do QIM.

Dos professores que responderam afirmativamente à questão: considera, que existem áreas curriculares / disciplinas em que o QIM se revela mais adequado? (QP 3.15.), 67,8\% $(n=527)$ tem essa opinião por considerar que "(...) há disciplinas que têm conteúdos mais adequados para ser trabalhados no QIM que outras" (Prof. 21) e "(...) há disciplinas onde o seu uso faz mais sentido pelas características das mesmas” (Prof. 23). Na verdade, "(...) há áreas em que não se justifica tanto o seu uso, como é o caso da educação física, onde a maioria das aulas são lecionadas ao ar livre ou em contexto de ginásio" (Prof. 817). Portanto, para esses professores ( $n=527)$, o uso do QIM depende da 'Natureza da disciplina'. Mais de uma centena de professores $(n=131)$, equivalente a $16,9 \%$, considera que o QIM é mais ajustado para certas disciplinas devido às suas 'Potencialidades técnicas', ou seja, "(...) o quadro está mais apetrechado com recursos para umas disciplinas do que para outras" (Prof. 1449) e os próprios "(...) softwares existentes são mais propensos para certas disciplinas" (Prof. 917). Um número menos significativo de professores referiu que o QIM é mais adequado a determinadas disciplinas do que a outras, porque numas 'Facilita a aprendizagem', o 'Interesse/motivação'; 'Aprendizagem de vocabulário', apresenta maior 'Disponibilidade de recursos' e 'Potencialidades didáticas' e noutras o seu uso não é tão relevante e profícuo. Segundo o Prof. 177 “(...) em certas disciplinas influenciará na aprendizagem, no interesse, no vocabulário e noutras será mais um recurso como tantos outros que existem".

No que respeita aos professores que consideram não existirem áreas curriculares/ disciplinas mais adequadas para o uso do QIM, a grande maioria dos professores $(89,5 \%$ ou $\mathrm{n}=621$ ) defende que este meio tecnológico pode ser utilizado em qualquer área disciplinar; 22,3\% ( $n=155)$ considera que apresenta 'Potencialidades técnicas', ou seja, “(...) recursos/ferramentas para que seja usado em todas as disciplinas" (Prof. 246); 12,2\% ( $\mathrm{n}=85$ ) refere que dispõe de 'Potencialidades didáticas' que “(...) permitem realizar uma versatilidade enorme de atividades e diversificar metodologias" (Prof. 759). As restantes razões apresentadas na tabela 5 para justificar que não existem áreas curriculares/disciplinas mais adequadas para o uso do QIM não obtiveram o mesmo nível de consenso entre os professores que as anteriormente expostas. No entanto, será importante referir que alguns professores manifestam essa opinião por considerarem que o uso do QIM 
depende antes do 'Conhecimento/Nontade do professor' ou porque acham que o seu 'Uso é importante' em qualquer área com as devidas 'Adaptações' já que 'Facilita a aprendizagem' e possui 'Recursos adequados'.

Os professores que consideram existir áreas curriculares/ disciplinas mais adequadas ao uso do QIM ( $n=777$, ou $52,8 \%$ ) referiram que as disciplinas mais adequadas para a sua utilização são essencialmente a Matemática, o Português, o Estudo do Meio e as Ciências da Natureza/ Ciências Naturais (Cf. Tabela 6). De todas as disciplinas lecionadas nos diferentes ciclos de escolaridade ${ }^{4}$, as Expressões (Expressão e Educação: Físico-Motora, Musicamática e Plástica) e o Apoio ao Estudo no 1.ำ ciclo e, a Educação Física no 2.ํ e 3.ำ ciclo foram as únicas disciplinas não indicadas adequadas para o uso do QIM por nenhum dos professores inquiridos.

Os restantes professores (47,2\%) consideram não existir áreas disciplinares/disciplinas mais apropriadas à utilização do QIM, já que pode ser usado em toda e qualquer disciplina por dispor de ferramentas/recursos (Potencialidades técnicas) para todas as disciplinas e possibilitar realizar variadíssimas atividades e diversificar metodologias (Potencialidades didáticas) em qualquer uma delas. Estes professores vão ao encontro do pensamento de Beltrão \& Nascimento (2000) já que consideram que a "introdução das TIC na escola deve ser feita durante toda a escolaridade e em todas as disciplinas" (p.187).

\footnotetext{
${ }^{4}$ As disciplinas do 1. ciclo segundo o Decreto-Lei n. $91 / 2013$ de 10 de julho (Diário da República, 1. série - N.은 131 - 10 de julho de 2013) são: Português, Matemática, Estudo do Meio, Expressões Artística e Físico Motora, Apoio ao Estudo e Educação para a Cidadania. As disciplinas do 2..$^{\circ}$ ciclo segundo o Decreto-Lei n.․ 139/2012 de 5 de julho_(Diário da República, 1. a série - N. 129 - 5 de julho de 2012) são: Português, Inglês, História e Geografia de Portugal no âmbito das Línguas e Estudos Sociais; Matemática e Ciências Naturais no departamento de Matemática e Ciências; Educação Visual, Educação Tecnológica, Educação Musical e Educação Física no âmbito da Educação Artística e Tecnológica e Educação Moral e Religiosa (disciplina de frequência facultativa, nos termos do artigo 15., parte final, com carga fixa de 45 minutos).As disciplinas do 3.응 ciclo segundo o Decreto-Lei n.․․ 139/2012 de 5 de julho_(Diário da República, 1. a série - N. 129 - 5 de julho de 2012) são: Português, Línguas Estrangeiras: Inglês, Línguas Estrangeiras II (normalmente Francês ou Espanhol) História, Geografia, Matemática e Ciências Naturais, Físico-Química; Educação Visual, TIC e Educação Física e Educação Moral e Religiosa (disciplina de frequência facultativa, nos termos do artigo 15.․, parte final, com carga fixa de 45 minutos).
} 
Tabela 6

\section{Áreas curriculares/disciplinas mais adequadas ao uso do QIM}

\begin{tabular}{lcc}
\hline Áreas curriculares/ disciplinas em que o QIM se revela mais adequado & Fr. & $\%$ \\
\hline Matemática & 586 & 75,4 \\
Português & 306 & 39,4 \\
Estudo do Meio & 224 & 28,8 \\
Ciências da Natureza/Naturais & 115 & 14,8 \\
Inglês & 93 & 12,0 \\
Físico-Química & 65 & 8,4 \\
Francês & 63 & 8,1 \\
Geografia & 55 & 7,1 \\
História e Geografia de Portugal/História & 45 & 5,8 \\
Espanhol & 37 & 4,8 \\
Educação Visual & 27 & 3,5 \\
Tecnologias da Informação e Comunicação & 18 & 2,3 \\
Educação Tecnológica & 10 & 1,3 \\
Educação para a Cidadania & 7 & 0,9 \\
Educação Musical & 2 & 0,3 \\
Educação Moral e Religiosa & $\mathbf{N}$ & 0,1 \\
\hline
\end{tabular}

Fonte: Elaboração própria, 2018

\section{Conclusões}

É incontestável: as TIC vieram alterar o cenário educativo. Apesar de uma grande percentagem dos professores em exercício de funções docentes serem imigrantes digitais (Prensky, 2001, p. 5), o estudo de Lopes (2015) revela que, na perspetiva da maioria dos diretores inquiridos, esses professores acabam por adaptar-se a este mundo, embora possam encontrar algumas dificuldades para sobreviver no mundo digital porque têm consciência de que é importante pensar em novos modelos metodológicos de ensino/aprendizagem para atenderem à demanda dos nativos, já que o modelo tradicional de ensino se torna incompatível com o perfil dos alunos que hoje temos nas nossas salas de aula. O desafio que se propõe a todos os docentes consiste, portanto, em adicionar os novos recursos à sua prática para aplicar novos conhecimentos com os alunos, já que parece lógico supor que a sociedade da informação e comunicação não vai regredir para a 
sociedade industrial e à sua forma de ensino característica, a da transmissão da informação. Os professores, com mais ou menos familiaridade com as tecnologias digitais, perceberam que não se podem opor a elas e, como diz um velho ditado popular, "se não puderes vencer o inimigo, alia-te a ele". Na verdade,

(...) uma peça de giz e quadro-negro ou mesmo um galho e um chão de areia são ferramentas nas mãos de um 'mestre'. Tais educadores podem ser professores da escola primária, instrutores militares, idosos de uma tribo ou educadores de outdoors usando suas ferramentas para ensinar um aspecto de sua cultura aos aprendizes. De modo similar, equipamentos de videoconferência ou computadores pessoais podem ser usados como ferramentas educacionais por educadores que saibam (a tecnologia de) como usá-las para propósitos pedagógicos. Ferramentas e tecnologias são tão fundamentais para educação que é difícil imaginá-la sem eles; especialmente os sons e símbolos como ferramentas e a escrita e a linguagem como tecnologias. (Evans, 2002, p. 3)

Concordamos com Terry Evans, porque efetivamente, hoje, o quadro preto, o giz e os livros já não podem ser os únicos instrumentos para o ensino, o que implica desenvolver um conjunto de atividades didático-pedagógicas a partir das outras tecnologias disponíveis na sala de aula. Aliás, hoje em dia, quando se usa a expressão "Tecnologias na Educação" dificilmente se pensa em giz e quadro negro, ou mesmo, em livros e revistas.

Nesse sentido, apurámos que a idade dos professores não influencia a utilização do QIM (Cf. Tabela 2), porque os professores têm encarado a sua integração como mais um desafio para conviver o mais harmoniosamente possível com os nativos digitais, transformando as suas práticas pedagógicas ancoradas nesta tecnologia. O nosso estudo deixa evidente que o professor apenas terá de se apropriar do conhecimento necessário (formação) e de estar predisposto para migrar para a cultura digital, tornando-se, portanto, um migrante digital, utilizando o QIM como ferramenta do processo de ensino/aprendizagem.

Dos dados que recolhemos, percebemos ainda que da perspetiva, quer de $93,3 \%$ dos diretores quer, de 1381 dos professores inquiridos, o ano de escolaridade lecionado pelos professores não influencia nem condiciona o uso desta TIC (Cf. Tabela 3 e 4), porque apresenta ferramentas/recursos/potencialidades adaptáveis a qualquer ano de escolaridade. No entanto, alguns diretores e professores afirmaram que de ano para ano devem ser feitas 
adequações para que o seu uso seja profícuo. Também Smith (1999) lhe reconheceu versatilidade, com aplicações para todos os anos de escolaridade em todo o currículo.

Os poucos professores segundo os quais a utilização do QIM depende do ano de escolaridade que se leciona, referiram que é mais adequado sobretudo ao 1.9 ciclo,

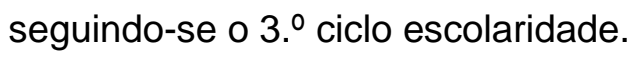

\section{Reflexão Final}

Percebe-se que, neste oceano emaranhado de dispositivos tecnológicos, o quadro interativo traz para a sala de aula novas possibilidades que pode envolver os alunos e professores, num ambiente de aprendizagem mais criativo, interativo e sobretudo dinâmico. Passaremos das aulas relativamente estáticas, onde os alunos tinham um papel de observadores e consumidores de conteúdos, para a "era" do som, movimento e imagem, com uma crescente participação dos alunos. Esta nova realidade revoluciona os modelos de prática letiva em vigor. A aprendizagem tradicional começa a ceder, em prol da aprendizagem centrada nas tecnologias hipermédia que incluem o quadro interativo multimédia (imagens e sons associam-se a textos e a outros sons e imagens). $O$ ensino caminha para um estado de construção e descoberta, no qual o professor passa de transmissor a facilitador da aprendizagem e a mera absorção de conteúdos programáticos dará lugar à crítica reflexiva de informação. Assim, é dada ao aluno a possibilidade de ser ele próprio a construir a sua aprendizagem, permitindo que se questione, atue e observe o produto da sua ação.

Lopes et al., (2016) verificam que há uma tendência de equipar as escolas com este recurso tecnológico, sendo que a taxa média deste equipamento no mundo permanece de 7\%. Porém, equipar as escolas com o QIM não é suficiente para garantir um salto qualitativo na educação, pois não podemos esquecer que o mais importante não é incorporar a tecnologia na aula, mas inovar e adaptar as metodologias. Acreditamos que o QIM possibilita a diversificação de atividades, mudanças metodológicas, cria novos cenários que facilitam o ensino/aprendizagem, e tornam a escola atrativa, atual e enquadrada nesta nova era da informação e da comunicação. Com o QIM e todos os recursos que a ele se podem associar, os intervenientes educativos (professor / aluno) têm ao seu dispor um rol extraordinário de escolhas em prol de uma educação de qualidade. Ao utilizarem essas ferramentas digitais procurarão superar a desmotivação tão vigente em contexto de sala de aula e granjearão a tão desejada sabedoria digital. Estas tecnologias podem constituir uma mais-valia na 
construção e partilha do saber e poderão romper com o ensino prisioneiro de uma pedagogia mais tradicionalista, pois franqueia "(...) aos professores a possibilidade de ensinarem de 'outro modo', permitindo pensar num paradigma metodológico que rompa com o modelo de pedagogia uniformizante" (Silva, 2001, p. 848).

Além disso, com a sua integração no contexto educativo podemos estar perante a oportunidade ímpar de diminuir a fratura digital e de facilitar uma articulação eficaz entre os digital immigrants e os digital natives (Prensky, 2001).

Segundo Escola et al. (2016), cabe ao professor escolher o dispositivo tecnológico a utilizar, a frequência de uso, o momento em que se quer integrar na sua aula mediante o tipo de alunos para quem se leciona e os conteúdos que se pretendem transmitir, dada a realidade das salas de aula nas escolas do $1^{\circ}$ ciclo do ensino básico ser muito diversa. Spínola (2009) e Ferreira (2010) aferiram que o quadro interativo desperta e motiva alunos de todos os níveis de escolaridade. Essa utilização deve ser feita nas diversas áreas curriculares disciplinares e, inclusive, nos domínios transversais, preconizados nos documentos curriculares de referência, adequando as metodologias a este novo contexto. No estudo realizado confirmamos que o QIM é empregado fundamentalmente nás áreas de Matemática, Português e Estudo do Meio. Em relação a isto podemos destacar um estudo realizado pela Agência Britânica de Comunicações e Tecnologias da Educação (Becta, 2006), que concluiu que o QIM tem um impacto positivo em alunos do ensino básico nas disciplinas do Inglês, Matemática e Ciências. Nesta linha, 47,2\% de professores considera não existirem disciplinas mais adequadas do que outras para o uso do QIM. Esta constatação não se revê nos dados que Bell (2002) e Becta (2003) apuraram, uma vez que uma das vantagens indicadas nos seus estudos era o reconhecimento de que este recurso tecnológico era versátil e adaptável a diferentes níveis etários e áreas curriculares.

Finalmente, ao democratizar o acesso a esta tecnologia, desbravaremos caminho para a inserção dos alunos e professores na sociedade da informação, do conhecimento e da aprendizagem. Não desejamos que os professores usem a sua sabedoria digital e não mudem as suas metodologias. Esta "janela para o mundo" não deve ser usada como apenas mais um recurso, mas antes como um recurso que pode melhorar as metodologias de ensino. Pretendemos que professores e alunos passem a atuar como produtores de cultura e de conhecimento e não como transmissores e recetores desse conhecimento. 


\section{Limitações e constrangimentos da investigação}

Procurando transformar algumas coisas incertas noutras um pouco mais plausíveis e legitimadas, percorremos este árduo caminho entre um fazer e desfazer, remates e alinhavos, entre conclusões e esboços de novas formulações, que se fundem na certeza das incertezas. Assumindo as palavras do poeta transmontano Miguel Torga: Até onde podia, caminhei... No entanto, o percurso desenvolvido para a elaboração do nosso estudo não escapou à existência de determinados fatores limitativos à sua realização.

Uma das primeiras limitações foi a falta de quadros interativos em muitas das escolas e a falta do seu uso por parte dos professores. O QIM é uma das mais recentes tecnologias ao serviço da educação em Portugal pelo que, ainda há muitos professores que não o usam pelas mais diversas razões, como vimos anteriormente. Desta forma tornou-se para nós mais difícil que os professores respondesses, pois diziam que não "falavam" do que não dispunham nas suas salas de aula ou do que não conheciam.

Outro constrangimento prende-se com a impossibilidade de flexibilidade do horário da investigadora. Considerando que o estudo exigia a ida a muitas escolas, a não obtenção de um horário mais flexível, foi extremamente prejudicial para a investigadora levar a "bom porto" este desafio. Na verdade, após o primeiro contacto com as escolas para apresentar o estudo e solicitar a colaboração no mesmo, era necessário insistir com o intuito de garantir que a esmagadora maioria dos professores respondesse aos questionários. A manifesta falta de tempo para essa deslocação dificultou o acesso a um número mais elevado de respostas. Tornou-se um processo moroso e exaustivo.

Efetivamente, não foi fácil conciliar o estatuto de docente em exercício de funções com a realização de todos os momentos e processos que uma investigação deste alcance exige. Apesar das limitações e dificuldades, o trabalho realizado pode constituir um desafio para novos (re)investimentos em processos geradores de um maior aprofundamento na área da integração do QIM na educação.

\section{Referências}

Bardin, Laurence. (2006). Análise de conteúdo (L. de A. Rego \& A. Pinheiro, Trads.). Lisboa: Edições 70. (Obra original publicada em 1977).

Becta ICT Research. (2003). What the research says about interactive whiteboards. Coventry: Becta. 
Becta ICT Research. (2006). Teaching interactively with electronic whiteboards in the primary phase. http://www.edubcn.cat/rcs gene/9 teaching interactively whiteboards.pdf

Bell, Mary Ann. (2002). Why use an Interactive whiteboard? A baker's dozen reasons! Teachers, net Gazette, 3(1). Recuperado de http://teachers.net/gazette/JAN02/mabell.html

Briggs, Asa e Burke, Peter. (2004). Uma história social da mídia: de Gutenberg à Internet. Rio de Janeiro: J. Zahar.

Coutinho, Clara. (2005). Percursos da Investigação em Tecnologia Educativa em Portugal uma abordagem temática e metodológica a publicações científicas (1985-2000). Braga: I.E.P.- Universidade do Minho.

Escola, Joaquim; Gomes, Anabela e Raposo-Rivas, Manuela. (2016). Integração das tecnologias da informação e comunicação no ensino português: um estudo de caso múltiplo. UT. Revista de Ciències de l'Educació, (2), 52-69. Disponível em: https://revistes.urv.cat/index.php/ute/article/view/656

Esteves, Joana e Lencastre, José Alberto. (Septiembre, 2013). Criação de Recursos Didáticos para Quadros Interativos Multimédia. Atas do XII Congresso Internacional Galego- Português de Psicopedagogia (CD ROM). Braga, Portugal: Universidade do Minho.

Evans, Terry. (2002). Uma revisão da educação superior a distância: uma perspectiva Australiana. In I Congresso de Ensino Superior à Distância. Petrópolis. Anais. Petrópolis: ESud.

Ferreira, Cláudia Fernandes. (2010). O uso do QIM nas aulas de língua estrangeira como elemento motivador. (Dissertação de Mestrado). Porto: Universidade do Porto.

Ferreira, Pedro Manuel Pimenta Gonçalves. (2009). Quadros interactivos: novas ferramentas, novas pedagogias, novas aprendizagens (Dissertação de Mestrado). Universidade do Minho, Braga, Portugal.

Folhas, Rute Cármen Reis Lopes. (2010). Formação de professores de ciências sobre Quadros Interactivos em regime de bLearning (Dissertação de Mestrado). Universidade de Aveiro, Aveiro, Portugal.

Gardner, Howard. (1999). O Verdadeiro, o Belo e o Bom. Rio de Janeiro: Objetiva.

George, Darren, and Mallery, Paul. (2003). SPSS for Windows step by step: A simple guide and reference. 11.0 update (4th ed.). Boston: Allyn \& Bacon.

Guimarães, Daniela e Carvalho, Ana Amélia. (2012). Formação de professores em quadros interativos Multimédia: um estudo de caso no centro de formação de Associação de escolas de Sousa Nascente. In: II Congresso Internacional TIC e Educação. Lisboa: Universidade de Lisboa. Disponível em: http://ticeduca.ie.ul.pt/atas/pdf/122.pdf 
Jonassen, David. (2007). Computadores Ferramentas Cognitivas. Desenvolver o pensamento crítico nas escolas. Porto: Porto Editora.

Lee, Mal. (2010). Interactive whiteboards and schooling: the context. Technology, Pedagogy and Education, 19(2), 133-141. Doi https://doi.org/10.1080/1475939X.2010.491215

Lopes, Natália. (2015). Quadro Interativo Multimédia: A Nova Janela para a aprendizagem no Ensino Básico - presença, usos e metodologias no Norte de Portugal (Tese de Doutoramento). Universidade de Trás-os-Montes e Alto Douro, Vila Real, Portugal.

Lopes, Natália, Escola, Jacinto e Raposo-Rivas, Manuela. (2015). O QIM como recurso no ensino básico do norte de Portugal: Estudo de boas práticas. UT. Revista de Ciències de l'Educació, (2), 7-26. Disponível em: http://goo.gl/g6Av7U

Lopes, Natália, Escola, Joaquim e Raposo-Rivas, Manuela. (2016). Quadro interativo multimédia: a integração na escola da nova janela para o mundo. En Joaquim Escola, Manuela Raposo-Rivas, Paula Aires y María-Esther Martínez-Figueira (coord.), Experiencias de investigación e intervención educativa con las TIC (pp. 45-56). Almería: Procompal.

Pardal, Luís A. e Correia, Eugénia. (1995). Métodos e técnicas de investigação social. Lisboa: Areal Editores.

Prensky, Marc. (2001). Digital natives, digital immigrants. In the Horizon, vol.9, ํ⒌

Quivi, Raymond e Campenhoudt, Luc Van. (2003). Manual de investigação em ciências sociais ( $3^{\underline{a}} \mathrm{ed}$.). Lisboa: Gradiva.

Raupp, Fabiano Maury e Beuren, Ilse Maria (2004). Metodologia de Pesquisa Aplicável as Ciências Sociais. In Ilse Maria Beuren (coord.), Como elaborar trabalhos monográficos em contabilidade: teoria e prática (2a. ed., pp. 76-97). São Paulo: Altas.

Rocha Silva, Cristiane, Christo Gobbi, Beatriz, e Adalgisa Simão, Ana. (2005). O uso da análise de conteúdo como uma ferramenta para a pesquisa qualitativa: descrição e aplicação do método. Organizações Rurais \& Agroindustriais, 7(1), 70-81.

Silva, Bento. (2001). A tecnologia é uma estratégia. In Paulo Dias e Varela de Freitas (org.). Actas da II Conferência Internacional Desafios 2001 (pp. 839-859). Braga: Centro de Competência da Universidade do Minho do Projecto Nónio.

Smith, Anna. (1999). Interactive whiteboard evaluation. MirandaNet,1999. Recuperado de https://mirandanet.ac.uk/blog/2015/01/13/interactive-whiteboard-evaluation/

Spínola, Teresa Maria Gomes. (2009). A utilização do quadro interactivo multimédia em contexto de ensino e aprendizagem Impacte do projecto "O Quadro interactivo multimédia na RAM" (Dissertação de Mestrado). Universidade de Aveiro, Aveiro, Portugal.

Vicente, Cristina Martins e Melão, Nuno Filipe. (2009). A adopção do quadro interactivo pelos professores de matemática do $3^{\circ}$ CEB: um estudo empírico nas escolas da Guarda. Educação, Formação \& Tecnologias, 2(2), 41-57. Disponível em: http://eft.educom.pt 